\title{
Evolution of the Physical Interfaces in Videogames as a Support to the Narrative and the Gaming Experience
}

\author{
Alan Richard da Luz ${ }^{1,2}$ \\ ${ }^{1}$ Centro Universitário SENAC, São Paulo, Brazil \\ ${ }^{2}$ Faculdade de Arquitetura e Urbanismo / USP, São Paulo, Brazil \\ Alan.rluz@sp.senac.br
}

\begin{abstract}
This paper proposes a classification of videogames by their physical interfaces (controls, keyboards, joysticks, mouse etc.) and how they interact with narrative complexity in videogames. By now, classifications of videogames never took into account of the play element and the aesthetic experience the player had with games. This analysis comprehends the commercial operation of the videogame industry, basically from 1971 to the present day. The classification proposed here is independent of the traditional ones, although there are some similarities and parallels.
\end{abstract}

Keywords: Videogames, interface, narrativity.

\section{Introduction}

The way that the generations of video games are classified has always been grounded in the capacity of graphic representation, which is determined by the technological apparatus and the processing capabilities [1]. Because of that, this type of classification never took into account the playful or gaming aspects involved in the act of playing, limiting itself to technical and material aspects. But when analyzing the experts who focus on play, we realized that the experience of meaningful play does not happen only in relation to that technical issues, but to a whole complex system involving both software and hardware, both the physical-material and the logical-digital.

This paper proposes a classification of videogames by their physical interfaces (controls, keyboards, joysticks, mouse etc.) and how they act in relation to the narrative complexity of these videogames. With this, it is expected the establishment of the relationships between these interfaces and the narratives in videogame, proposing a classification based on the link between gaming experience and its interface with the player. It is important to explain that this classification is independent of the traditional ones, such as the one proposed by Luz [1], although there are some similarities and parallels. This independence should be observed mainly by the proposition of a more targeted approach to user experience in relation to the narrative and interface.

The time frame of this analysis comprehends the commercial operation of the videogame industry, from 1971 to the present day. With this definition, it is set aside the laboratory experiments, such as William Higinbotham's in 1958, with his Tennis for 
Two and isolated experimental projects such as the game Spacewar!, developed by MIT students in 1961/1962.

\section{The Particularities of the Narrative in Videogames}

It is deemed appropriate a clarification related to the narrative within the videogames, given the fact that it happens in a very particular way in relation to traditional media (books, movies, orality). As Jesper Juul points out:

If we play Space Invaders [...] we are presented with an ideal story that we have to realize using skill. [Space] Invaders suggests a prehistory: an invasion presupposes a situation before the invasion. It is clear from the science fiction we know that these aliens are evil and should be chased away. So the title suggests a simple structure with a positive state broken by an external evil force. It is the role of the player to recreate the original positive state. This is, of course, a sequence often found in folk tales: an initial state, an overturning of this state, and a restoration of the state.

$[\ldots]$

But it works in a different way. If we play Space Invaders, we find that we cannot actually restore the initial state; we cannot win, because every wave of aliens is followed by another. As players we are fighting to realize an ideal sequence of events, but the actual playing is not this sequence. [2]

The game presents us with an ideal narrative, but it only happens with the interaction of the player. The basic narrative of the game Super Mario Bros is a classic princess' rescue in the castle of the monster, but it will only take place if you reach the end of the game. In diying in the game, the player ends narrative there, having to restart it.

The player action and decisions are crucial to the unfolding of these narratives, and these actions are mediated by controls (physical interfaces), which play a fundamental role in the relationship between the player and the game.

Playing a game means interacting with and within a representational universe, a space of possibility with narrative dimensions. [...] Formed by rules and experienced through play, a game is a space of possible action that players activate, manipulate, explore, and transform.[3]

With this assumption, it is proposed an analysis and classification of the videogames generations by the characteristics of its physical interfaces, analyzing the possibilities of interactions with the narratives in videogames to which they are connected. Several types of controls and physical interfaces have been proposed in all the history of videogames, and each one of them brings particularities related to the possibilities of interactions with the related narratives. 
Moreover, the development of the controls was also influenced by the introduction and evolution of the use of these narratives. The quantity/quality of the possibilities improved first with the introduction of an internal narrative and then with the complexity of the stories. Without the development of the controls and their physical interfaces, interaction with the narrative would be very difficult if not impossible in the universe of videogames.

A story is best envisioned as "beads on a string", a linear narrative; a game is best envisioned as a triangle os possibility, with the initial position at one apex, and possible conclusions along the opposite side, with myriad, ideally, infite paths between initial state and outcome. To the degree that you try to make a game more like a story by imposing arbitrary decision points, you make it less like a game. [3]

Another important issue is the relationship video game/narrative and how this discussion has been wide and controversial, it was opted in this paper to assume that video games offer narrative possibilities and, in general, they tell stories. The approach and terminology used here is in accordance with Salen \& Zimmerman [3] and Juul [4].

\section{First-Generation Controls - Few Options and External Narrative}

At first, in games like PONG (Atari, 1973) or BREAKOUT (Atari, 1976), the narrative was external to the videogame itself. The narrative evidences were only available through external context of the game: illustration in the arcade cabinet of a prisoner escaping from prison in the case of BREAKOUT or just the name as an index that the game is an attempt to simulate a sporting activity, as in the case of PONG.

In addition to the inability at that time to graphically represent these situations, the games were based on mechanics of repetition, requiring speed and dexterity in the movements. This technical limitation in graphic representation also influenced the internal narrative offered by these games, which was non-existent. Even though arguments were offered (outside the game itself) for association with certain sports or situations, their connection with the narrative universe was limited to that.

The control interfaces of these games followed the logic of the indoor and electromechanical games: there were buttons with two positions (on/off) or analogical rotary dials. These controls limited our response to binary control, yes/no. Even when dials were driven by potentiometers (with an analogical nature), the response obtained was directional and also binary (up or down, in the case of Pong).

This limitation in the control of the game was enough for the proposed gameplay, but its limitation as to the possibilities of decision makes it insufficient for interaction in a narrative universe. The absence of narrative did not demand a more complex form of control because the decision tree in the game was also limited. Playing a table tennis match can provide a beautiful narrative proposition but when limiting the game to a given aspect, in the case "to bounce a ball", also limits the demand of the controls. 


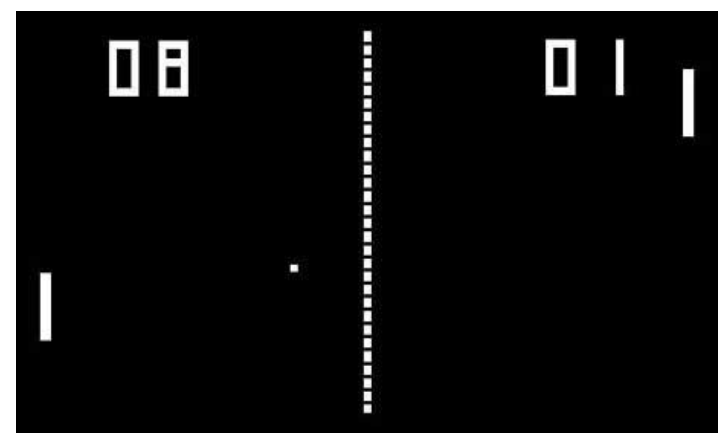

Fig. 1. PONG screenshot (Atari, 1973) - the game of table tennis is reduced and abstracted to the action of bouncing a ball (actually a square, given the inability of the graphics hardware) and the rackets are two small rectangles that are controlled by rotary dials (Source: screenshot by the author)

In the games that use these interfaces, any possibility of emergent narrative happens through the gaming experience of the player and other external elements (contextual). Or, as defined by Salen and Zimmerman, the narrative is "structural":

[in a Thuderstorm game] The experience of the game's "story" is intrinsically structural, tied directly to the game events. The roll of the dice not only controls the rate at wich a player's house is built, but simultaneosly the speed at wich the storm approaches. [5]

There is not a narrative to be "fulfilled" in the game, but a narrative that emerges according to the player's actions in the game, defined by the game's formal structure. The physical interfaces of games like PONG only allow structural narratives like these.

\section{Second Generation - The Joystick (or control lever) and the Beginning of the Internal Narrative}

The development of the videogame technology has brought new themes and a new type of control, the joystick (or control lever). Its appearance in videogames occurred with the release of TANK (Kee Games, 1974) and was based on the controls of a real war tank.

Despite the controls having each one only two positions, the combination of the movement of the two offered to the system, four possibilities of decision: stopped, move forward, move left and move right. The scheme of movement can be seen in Figure 02. 

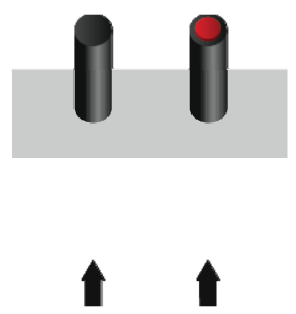
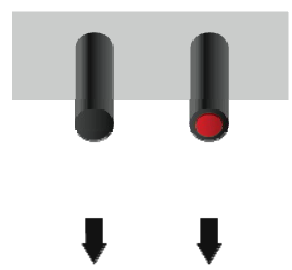
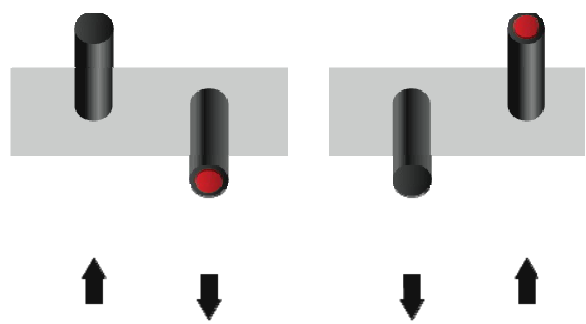

Fig. 2. TANK control scheme: Tank moves forward, tank don't move, tank goesright, tank goes lef

The decision tree increased, but the narrative was still offered externally to the game and the story experience happened in a similar manner to the first generation because the technology had not yet provided advances in the representation/narrativity. The game TANK! did not offer much in terms of narrative, but shortly afterwards, controls that offered more control positions were launched, still using the same interface based on the lever, which are known as joysticks.

The control lever of the game TANK! evolved into the well-known Atari VCS joystick, which popularized this type of interface in videogame consoles. His 8 digital positions joystick plus a push button made possible the movement throughout all the Cartesian space of the screen, thus increasing the decision tree of the player and allowing the emergence of games like Adventure (Atari, 1979).

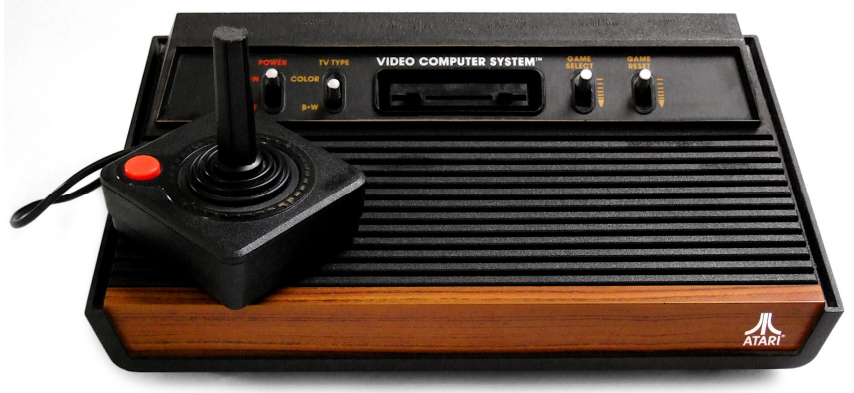

Fig. 3. Atari VCS and its popular joystick (Source: http://upload.wikimedia.org/wikipedia/ commons/d/dc/Atari2600a.JPG)

Controlling the character in the screen in a "free" way within the two-dimensional space, associated with the evolution of videogames, has brought new narrative possibilities to the games. The major criticism was the lack of precision of commands since the ergonomics are not the strong point of this interface. Exception must be made to the control of the arcades of that time, which despite eight-position levers, offered better grip and ergonomics, and a higher precision in the movements. 


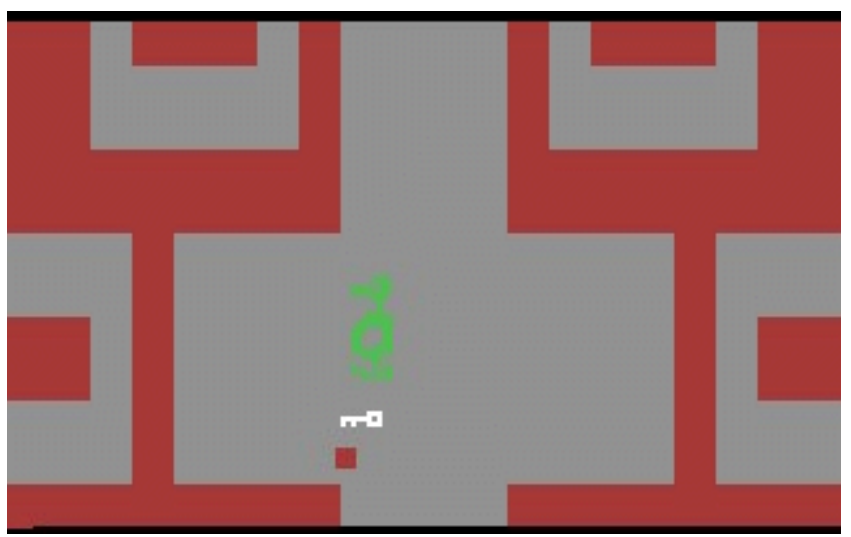

Fig. 4. The game Adventure of Warren Robbinet to the Atari VCS was based on exploration games with textual interface played in mainframes of the 1960s and 1970 (Source: http://upload.wikimedia.org/wikipedia/en/f/f3/Atariadventure.png)

\section{Third Generation - The Introduction of the D-Pad and the Precision of the Fine Movement}

The eight-position controls, such as the Atari VCS joystick, became standard and the natural evolution came by the hands of Gunpei Yokoi, in the Japanese Nintendo. By proposing a video game console that could be transported, he had to develop a reduced version of this eight-position interface that would work with the use of fingers solely.

His creation was then the namely "D-Pad", which like the Atari VCS control had eight positions, but since it was triggered by the thumb it was more accurate and allowed more subtle movements. His creation was launched on Nintendo's Game \& Watch series, and since then became the standard on consoles that followed in the 80 's.

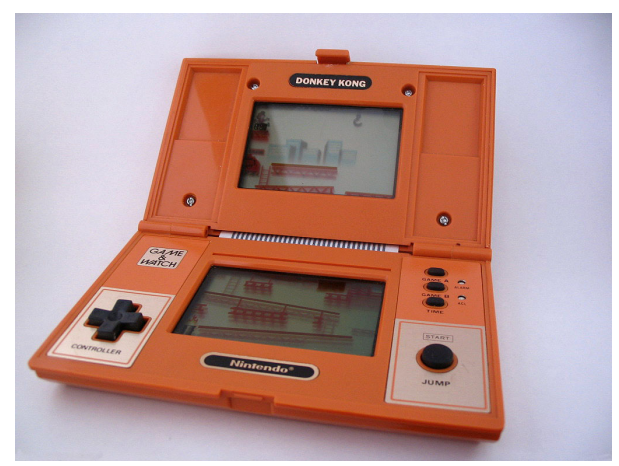

Fig. 5. Donkey Kong and the first D-Pad control, of Gunpei Yokoi (Source of the image: http://yesteryearremembered.com/wp-content/uploads/2011/02/Donkey_kong_game_and_watch.jpg) 
Options to the D-Pad, such as the Intellivision controller, which was controlled by a disc that allowed sixteen positions and was also activated by the thumb, will be disregarded in this study since they have not been consolidated as a commercial alternative.

The accuracy and comfort provided by Yokoi's directional control opened the doors to a new range of games that demanded more time of the player (controls until then were not ergonomically comfortable and the fatigue generated did not allow long periods of play).

With more time, the designers that then had in hands a better representation technology (like bitmapping technology and more colors in the display) and more memory (allowing larger game programs) could begin to propose internal narratives, beyond the external propositions and context.

The first to explore it extensively was Shigeru Miyamoto, Nintendo's game designer, who decided to develop his Donkey Kong in the form of a narrative. And believing that videogames could tell a story, made this narrative internal to the game.

He based his gaming concept in a mixture of narratives: King Kong and Popeye, and developed the personality of their characters so that it was confirmed by their action in the game. The hero Jumpman (which was renamed to Mario upon the arrival to the USA), as the name itself indicates, should be able to jump to overcome obstacles and be able to move in all directions, and in this regard the eight-position control plus the action button of the arcades was essential to the amount of choices support Jumpman's personality.

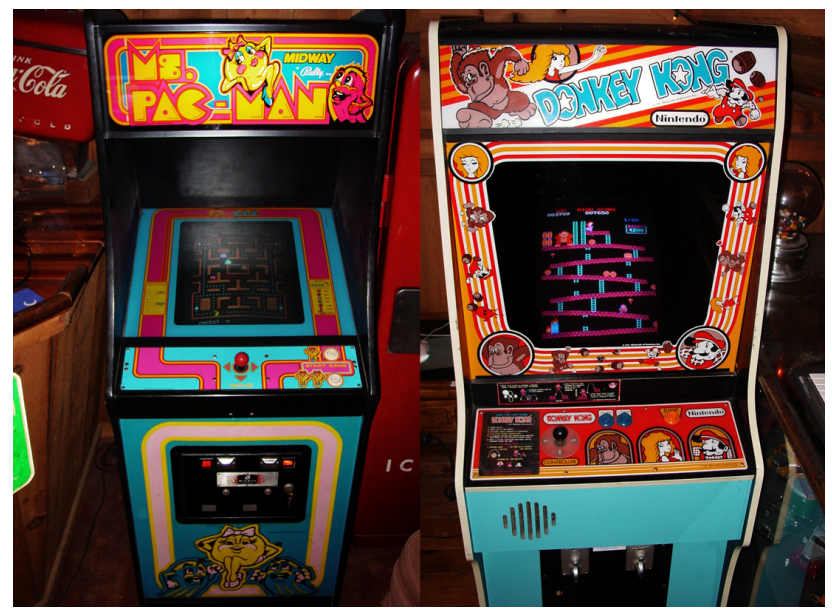

Fig. 6. Arcades of Ms.Pacman and Donkey Kong: games that built the personality of their heroes with the support of eight-position directional controls plus an action button (Source: http://commons.wikimedia.org/wiki/File:Ms._Pac-Man_\%26_Donkey_Kong_-_arcade_cabinets.jpg)

The characters with name and personality started to appear in early 1980s, when videogame designers explored the eight-position control in their full potential, combining them to one or more action buttons. The complexity and internalization of narratives could only happen in an environment that brought this complexity to its physical interface. 


\section{Fourth Generation - The "Introduction" of the Analog Control and the Real Freedom of Three-Dimensional Space}

The next step in the sophistication and complexity increment of controls occurred in the evolution of videogames with the introduction of navigable spaces in three dimensions, a concept that emerged with the release of 32-bit videogames in the early 1990s.

The exploration of this space, made possible through the addition of a z-axis, required a type of physical interface more appropriate to the freedom of movement in 360 degrees. Again this evolution was introduced by Nintendo (or reintroduced, since it was a known technology incipiently employed) who built the control to its Nintendo 64 console for the game Mario 64.

Mario 64 was the first platform game to explore the three-dimensional space in a free way in its full potential. When designing the control based on this game, Nintendo decided to use of the analog stick for believing it to be more suitable for this type of exploration.

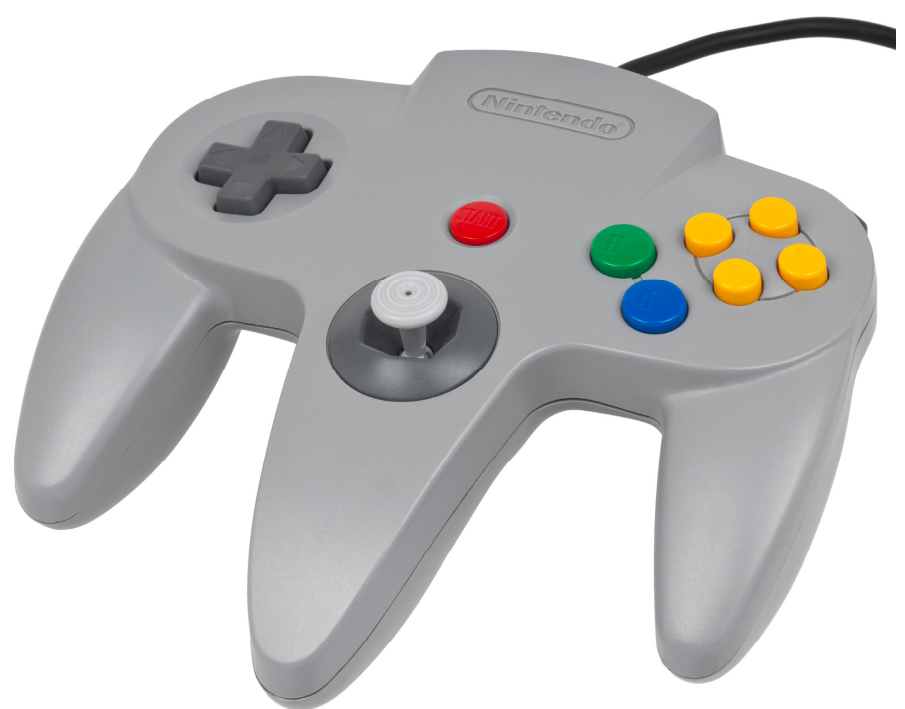

Fig. 7. The controversial control of the Nintendo 64, which allowed different grips for different types of games offered (Source: http://en.wikipedia.org/wiki/File:N64-Controller-Gray.jpg)

The analog stick actually proved more suited to three-dimensional environment and was soon afterwards adopted by other console manufacturers (Sony and Sega for example) and coupled with increasingly complex controls like the Dual Shock for the Playstation, that brought two analog levers plus a vibrational response.

The Playstation Dual Shock control was a natural evolution and arose amid the popularity of games with sandbox technology (full freedom of movement within the three-dimensional diegesis of the game) like Grand Theft Auto 3. Moving from a 
character with a personality shaped by its creators for a character whose personality could have been drawn by our actions within the game.

The complexity of this control was essential to this evolution of narrative, becoming increasingly distant from the narrative only to justify the action of the game as in PONG. This sophistication of the control allowed action on the complex anatomy and freedom of movement of the characters, which could now wander within a three dimensional space independently moving head, trunk and limbs, this way creating a personal signature move.

The aesthetic experiences achieved at this point demanded total control over the characters and the environments of the game, the strategies and tactics employed includes the physical interface and these character personal signature movement was part of it. Even in games where the narrative is only emerging as sports simulations, the addition of controlling capability allowed immediate access to more features/mechanics within the game environment.

\section{Fifth Generation - The Freedom of Multimodal or Gestural Interfaces}

The evolution brought by the three-dimensionality and sophistication of controls had other consequences, such as the expelling of the casual gamer. The games increasingly resembled large interactive narratives and the complexity of the controls made gaming difficult for those who just wanted a quick play of any game, or who had no familiarity with videogames, reaching then a deadlock. At the point where the interfaces become more sophisticated, they became less intuitive, and counting all the buttons and levers on a Dual Shock Control we reach a number of 14 controls (greater than the number of fingers on our two hands). This averted many potential players.

Nintendo once again was responsible for the introduction of an innovation by launching gesture control in its Nintendo Wii, which made the interface mediation something more transparent and intuitive. By the way, gestural interfaces were not new and were already being discussed in experimental environments since the 1970s.

In recounting the experience of observing a ship admiral giving orders for a subbordinate, Nicholas Negroponte highlights what he calls a "multimodal interface":

He [the admiral] knew that the sailor was contemplating the situation through the keyhole. [...] So he'd rather interact with a large map on the wall, [...] in which he pinned little ships. [...] The admiral felt good using the map, not because it is an old-fashioned resource and in ultra-high resolution, but because it could be done with the whole body. [6]

Using the whole body as the admiral or when using the Nintendo Wii, we employ many competing communication channels which makes the whole process more intuitive. Using the body allows us to have a more direct and non-mediated action with the relevant action in game, making this mediation more transparent, improving the perception of immersion in the narrative. 
The emergence of other consoles with this type of technology as the Playstation Move or Xbox Kinect proves the trend that more direct and seemingly non-mediated interactivity enriches the experience of immersion in these three-dimensional spaces.

When performing an action in the game diegesis through the emulation of this same action in the external environment, the attention paid to the game can be relieved and directed to the narrative elements of the game. Thus making the mediation more transparent and intuitive while infinitely more complex, since now we do not have the limit of number of buttons or levers, we use the whole body.

\section{Considerations}

The purpose of this paper is to make clear the link between the complexity of the forms of mediation in a videogame and narrative capacity of these, showing how their evolution occurred in parallel and in direct proportion. By creating games with immersive environments and more sophisticated narratives, it is inevitable to offer a way to properly deal with this world. It is impossible to imagine an interface for games with strong narrative appeal as ICO (SCEA, 2001) or sandbox technology as Grand Theft Auto V (Rockstar Games, 2013) as simple and as with many limitations as the rotary dial in PONG!.

The evolution of the physical interfaces in videogames makes clear the link between interaction technologies and the development of narrativity in videogames though it seems that there ins't a direct relationship between controls and narratives but rather between controls and graphic representation capacity. Even without the evolution of controls, the evolution of narrative in videogames could be menaced, once representativity is what seems to have been really driving the evolution of physical interfaces.

With this small study we intend to show the importance of proper planning of the construction of physical interfaces in videogames always taking into account the proposed narratives. When developing a game design document for a video game, it should be observed how the narrative emerges in the context of the game and how it is experienced by the player, and then develop this interface. Interface generations presented here follow a chronological sequence but this does not invalidate the use of simpler interfaces depending on the proposed narrative context.

\section{References}

1. Luz, A.R.: Video Games: História, Linguagem e Expressão Gráfica. Editora Blucher, São Paulo (2010)

2. Juul, J.: Games Telling Stories? In: Raessens, J., Goldstein, J. (eds.) Handbook of Computer Game Studies, pp. 219-226. MIT Press, Cambridge (2005)

3. Salen, K., Zimmerman, E.: Rules of Play: Game Design Fundamentals, p. 379. MIT Press, Cambridge (2004)

4. Juul, J.: Games Telling Stories? In: Raessens, J., Goldstein, J. (eds.) Handbook of Computer Game Studies, pp. 219-226. MIT Press, Cambridge (2005) 
5. Salen, K., Zimmerman, E.: Rules of Play: Game Design Fundamentals, pp. 381-382. MIT Press, Cambridge (2004)

6. Negroponte, N.: A Vida Digital, p. 88. Companhia das Letras, São Paulo (1995)

7. Donovan, T.: Replay - The History of Video Games. Yellow Ant Publishing, East Sussex (2010)

8. Game Studies: International Journal of Computer Game Research, http: / /www.gamestudies.org

9. Herman, L.: Phoenix: Rise and Fall of Videogames. Rolenta Press, New York (2001)

10. Kent, S.L.: The Ultimate History of video games: from Pong to Pokemon, the story behidn the craze that touched our lives and changed the world. Three Rivers Press, New York (2001)

11. Kohler, C.: Power Up - How japanese video games gave the world an extra life. Pearson Education, Indiana (2005)

12. Mäyrä, F.: An Introduction to Game Studies: Games and Culture. SAGE Publications, Londres (2008)

13. Poole, S.: Trigger Happy: Videogames and the Entertainment Revolution. Arcade Press, New York (2000)

14. Retro Gamer Magazine. Imagine Publishing, Dorset (2004)

15. Sellers, J.: Arcade Fever: The Fan's Guide to the Golden Age of Video Games. Running Press, Philadelphia (2001)

16. Wolf, M.J.P.: Abstraction in Video Games. In: Wolf, M.J.P., Perron, B. (eds.) The Video Game Theory Reader. Routledge, London (2003) 